patient is encouraged to flex the fingers at frequent intervals against the pull of the elastic, and as he relaxes the flexor tendons are stretched.

\section{The After-treatment of Burnt Hands}

The rehabilitation of patients with burnt hands requires much patience and perseverance. Provided that the tendons and joints of the fingers have not been destroyed, the degree of recovery that is possible may exceed all expectation. The first thing is to assure the patient of this, and the second is to see that he works away at his stiff joints all day long. Whatever the initial treatment has been after burning, the skin is usually very thin and tender and sweats profusely. The stiffness is due to general adhesion formation around the tendons and joints of the fingers, and is caused by the initial reactionary oedema. The fingers are usually straight as the result of splinting. Movement is regained by immersing the hand in olive oil or in paste made with fuller's earth, which is heated to a temperature of $110^{\circ} \mathrm{F}$. for two sessions of fifteen minutes daily. The patient is encouraged to squeeze a piece of rubber sponge or a ball while his hand is being heated. For the rest of the day he wears a detachable splint which dorsiflexes his wrist, and a glove to the finger-tips of which are attached lengths of elastic that are tied around a hook in the splint (Fig. 5). The constant pull of the elastic tends

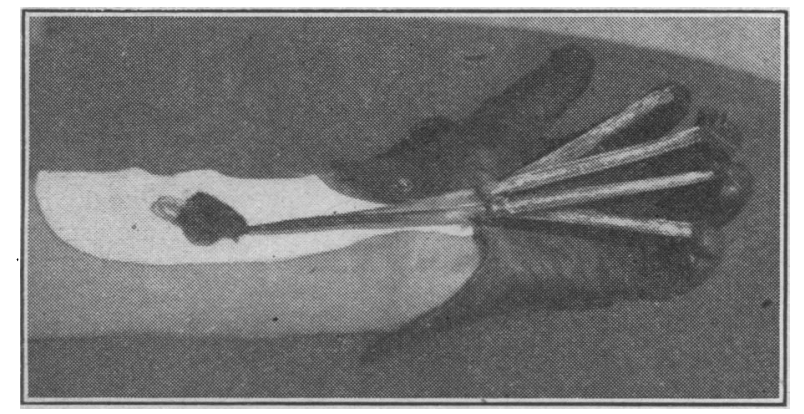

FIG. 5.-Flexion splint to overcome stiffness after burning.

to flex the fingers, and the patient is encouraged at all times to oppose this by extending them. Treatment may take many weeks, but to regain the use of a hand justifies any amount of trouble.

\section{Summary and Conclusions}

In this paper the principles underlying the rehabilitation of injured air crews are described. Orthopaedic casualties are transferred to a rehabilitation centre after having received necessary surgical treatment in an orthopaedic hospital. Some of these would probably work out their own salvation without further supervision, but others would certainly prolong their incapacity unnecessarily. These casualties are therefore kept under almost constant supervision in order to restore maximal function and make as many as possible fit for further flying duties, and also to curtail incapacity.

Each patient is studied individually, for with his cooperation graduated remedial activity will restore function more rapidly than any form of passive treatment. Muscular wasting and stiffness, associated with immobilization, are prevented to a great extent by active contraction. A fracture is no reason for neglect of the soft tissues.

The criteria by which successful rehabilitation is judged are : first, the category of the patient on returning to duty ; and, secondly, the time that he takes to regain function. Figures are as yet inconclusive, but $16 \%$ more patients were discharged to flying duties during the first six months that this department was working than during the six months before it opened.

\section{TREATMENT OF HAEMORRHAGIC DISEASE OF THE NEWBORN*}

\author{
BY
}

\section{A. I. S. MACPHERSON, M.B., Ch.B., F.R.C.S.Ed.}

Clinical Tutor, Royal Infirmary, Edinburgh; Crichton Research Scholar

The recognition of extreme prothrombin deficiency as by far the most frequent cause of spontaneous haemorrhage in the newborn and the discovery that vitamin $\mathrm{K}$ is essential for the maintenance of the normal plasma prothrombin level have raised to the status of a specific deficiency disease what had perforce been accepted as a mishap which " occurs without apparent reason" (Tallerman, 1937). Previously the only positive findings had been the report of Whipple (1913) that he had seen no prothrombin in a specimen of blood obtained after death from a fatal case of neonatal haemorrhage, and the observation that the clotting time tended to be prolonged for the first five days of life, returning to normal about the tenth day (Rodda, 1920). The treatment of haemorrhagic disease was correspondingly vague, the earlier clinicians advising local application of styptics, and, in the case of bleeding from the cord, even encircling the umbilicus with a deep suture. Injections of gelatin solution and of whole blood intramuscularly were introduced about the same time. This latter measure, despite the early recognition that spontaneous recovery from the haemorrhagic state occurred often enough to make its therapeutic value doubtful (Schloss and Commiskey, 1911, 1912), is still widely used as a routine treatment.

In the severer cases there has been general agreement that blood transfusion is a more efficacious procedure. The introduction of vitamin $\mathrm{K}$, and more especially of vitamin $\mathrm{K}$ analogues, into clinical practice, and the demonstration of the rapid elevation of the prothrombin index which follows the administration of these substances to the newborn (Macpherson et al., 1940), suggested another and apparently specific line of treatment for haemorrhagic disease, the successful use of which has already been reported in Europe and America (Nygaard, 1939 ; Waddell and Guerry, 1939 ; and others).

Since profound hypoprothrombinaemia is now recognized as the characteristic abnormality of the blood in haemorrhagic disease of the newborn, it follows that the efficacy of any method of treatment can be measured by its capacity (1) to raise the prothrombin content of the plasma so rapidly that the haemorrhage stops in a short time; and (2) to maintain the prothrombin at șo nearly a normal level that the haemorrhagic tendency does not recur.

This communication reports an attempt to evaluate by these standards the merits of intramuscular injection of whole blood, blood transfusion, and injection of vitamin $\mathrm{K}$ analogues as treatment for haemorrhagic disease of the newborn.

\section{Method Used}

All prothrombin estimations have been made upon capillary blood by a modification of the method evolved in this hospital (Innes and Davidson, 1941) and found to give results closely comparable to those obtained by methods requiring the use of venous blood (Quick et al., 1935; Ziffren et al., 1939). The test has been performed as originally described except that (9) the oxalated blood has always been diluted with four times its own volume of saline; (2) the solutions have been kept at a constant temperature; (3) the lecithin-venom solution described by Hobson and Witts (1940) has been preferred, as it was

\footnotetext{
* Part of the expenses of this investigation has been defrayed by a grant from the Earl of Moray Endowment.
} 
found to give a more definite end-point for the lower values of prothrombin. All results have been expressed as the "prothrombin index" (Illingworth, 1939) and charted as percentages of normal.

\section{The Investigation}

Ten cases of true haemorrhagic disease of the newborn have been treated by injection of whole blood into the buttock, by blood transfusion, or by injection of vitamin $\mathrm{K}$ analogues. The results of each line of treatment are reported in the first three sections below. Two cases of icterus gravis (erythroblastosis foetalis) also developed spontaneous and persistent haemorrhages, the treatment of which is briefly recorded in the fourth section.

\section{INTRAMUSCULAR INJECTION} OF WHOLE BLOOD

Intramuscular injection

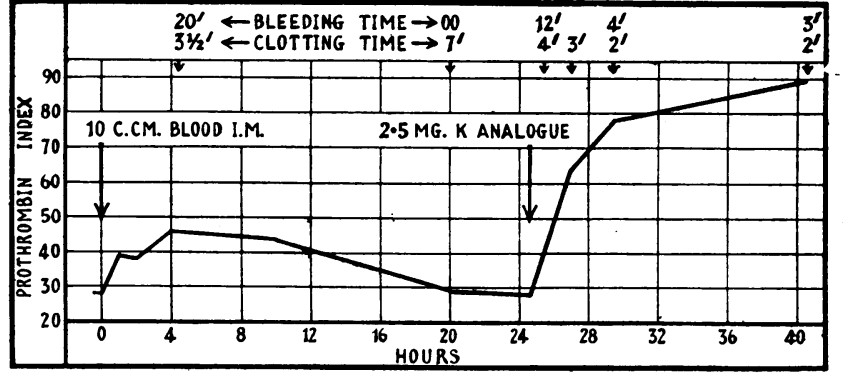

Fig. 1.-Case 6531 to have risen to 12 minutes, and the prothrombin index had fallen to a level lower than it had been before treatment. Bleeding had persisted from heel-stab throughout this time, but stopped two hours after the injection of vitamin $K$ analogue intramuscularly (see below).

The elevation in the prothrombin index obtained by the intramuscular injection of whole blood has proved to be so slight and so transient that only in Case 6531 did it even temporarily affect the course of the haemorrhagic disease. Moreover, in Case 7252, in which repeated injections were given, the temperature was raised to $101^{\circ} \mathrm{F}$. or over during the ensuing thirty-six hours and both buttocks were tense and painful. The risk of this procedure in less favourable surroundings is obvious.

\section{Blood Transfusion}

Two cases have been treated by whole fresh of whole blood has been employed in three cases. The effect upon the prothrombin index and upon the haemorrhagic manifestations is shown in Figs. 1, 2, and 3.

Case 6531.-Primipara. Normal labour (duration 21 hours); spontaneous delivery. Birth weight, $6 \frac{1}{2} \mathrm{lb}$. Birth condition satisfactory. Haematemesis (red and altered blood) at 32 hours of age. $10 \mathrm{c.cm}$. whole blood into buttock. Clinical condition did not improve. Haematemesis continued till further treatment with vitamin $\mathrm{K}$ analogue was given twenty-five hours later.

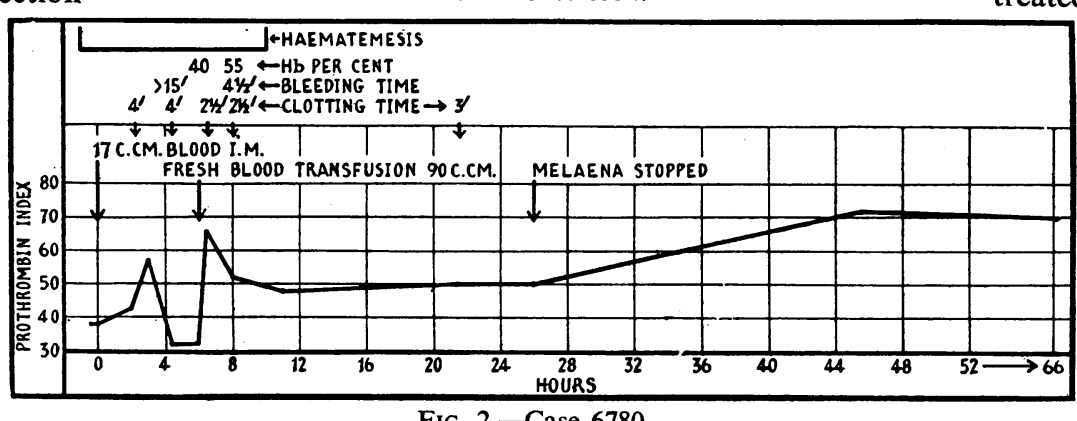

FIG. 2.-Case 6780.

Correction: 55 haemoglobin should be over $2 \frac{1^{\prime}}{2}$ and 66 .

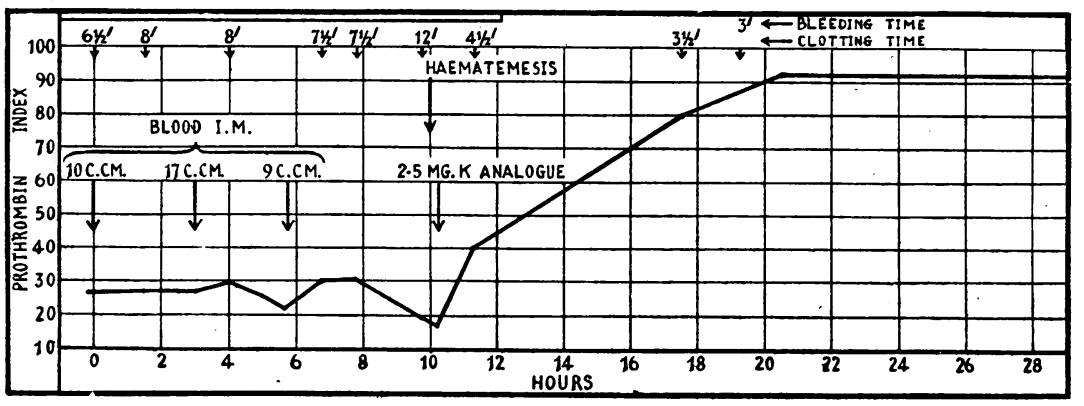

FIG. 3.-Case 7252.

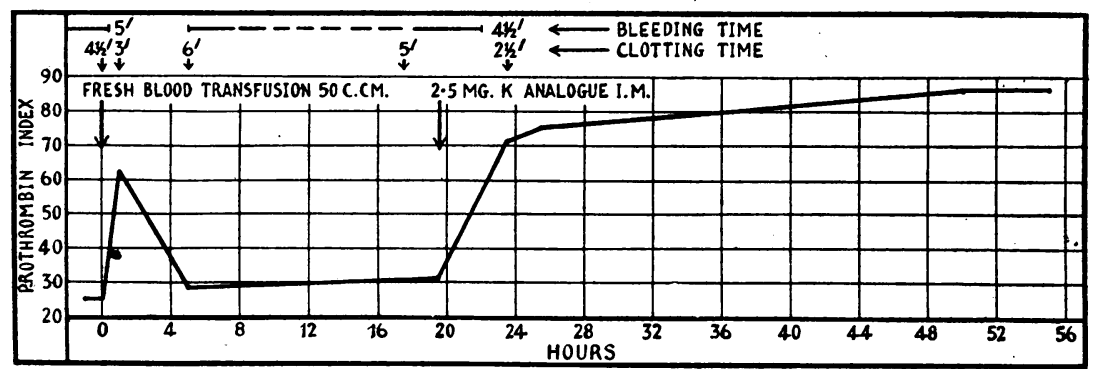

FIg. 4.-Case 6947. blood transfusion (Figs. 2 and 4).

Case 6780 (continued).-So much blood had been lost from the alimentary canal that haemoglobin was $40 \%$ at 38 hours. $90 \mathrm{c.cm}$. of whole blood transfused into superior sagit ta l sinus. Approximately an hour later haemoglobin was $55 \%$ and prothrombin index 66 , and all superficial bleeding had stopped. The last vomit of altered blood appeared 90 minutes later, and melaena lasted till approximately 56 hours. Cyanosis and restlessness were pronounced af ter the transfusion, the latter being controlled only by repeated doses of chloral.

Case 6947.--Primipara. Assisted breech delivery after 36 h o u rs' l a bour. Melaena appeared and oozing from abrasion on scrotum began at about 90 hours of age. Transfusion of $50 \mathrm{c.cm}$. into buttock at 32 hours. Bleeding continued with increasing pallor, so that transfusion was required at 38 hours.

Case 7252.-Primipara. Occipito-posterior position requiring

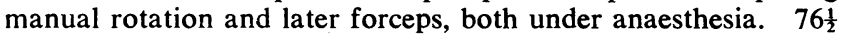
hours' labour. Birth weight, $8 \frac{1}{4} \mathrm{lb}$. Glucose-saline followed by one feed of breast milk and water $\bar{a} \bar{a} 1 \mathrm{oz}$. Haematemesis first occurred at 32 hours of age. Gastric lavage 10 hours later gave return of frank blood. $10 \mathrm{c.cm}$. whole citrated blood into buttock at 49 hours, $17 \mathrm{c.cm}$. at 52 hours, and $9 \mathrm{c.cm}$. at 55 hours. Four hours later haematemesis recurred, the clotting time was found whole blood into superior sagittal sinus at 96 hours. Bleeding stopped at end of transfusion, but recurred 5 hours later and persisted (soaking the dressings applied) for 12 hours till further treatment was given (see below).

Both cases were characterized by a rapid improvement in the prothrombin index and by the early cessation of bleeding. In both, however, subsequent readings showed an almost equally rapid fall in the prothrombin index. This fall was arrested in Case 6780, a level (about $50 \%$ ) 
above the bleeding threshold persisting for about twenty hours before further, apparently spontaneous, elevation occurred. To this case a very large transfusion (approximately one-third of its own blood volume) had been given. In Case 6947, in which the estimated blood volume was about five times greater than the volume of blood transfused, the prothrombin index fell almost to its original level and bleeding recurred five hours after the transfusion had been given.

\section{Injection of Vitamin K analogues}

Vitamin $\mathrm{K}$ analogues have been given by injection to six cases (Figs. 1, 3, 4, and 5). Fig. 5 shows the effect obtained clinically and upon the prothrombin index by intramuscular injection of $2.5 \mathrm{mg}$. of 2-methyl-1:4-naphthoquinone in oil (B), and by intramuscular injection of $5 \mathrm{mg}$. (A) and the intravenous injection of $2.5 \mathrm{mg}$. of water-soluble 2-methyl1 : 4-naphthohydroquinone disuccinate $(C)$. In each instance bleeding was controlled within about two hours. The prothrombin index curves show a rapid and remarkably parallel rise to a high level, which was subsequently maintained throughout the whole of the neonatal period. So far as can be judged, intravenous injection does not produce better results than deep intramuscular. It is important to give the oily solution deeply, as too superficial an injection will promote irritative local lesions.

Case 5754.-Primipara. Easy 10-hour labour with spontaneous delivery of $4 \frac{1}{4}-1 b$. child following medical induction for pre-eclamptic toxaemia. Clinical jaundice with pale faeces appeared on fourth day and steadily deepened. Bleeding from heel-stab persisted from 156 to $165 \frac{1}{2}$ hours. $5 \mathrm{mg}$. 2 - methyl - $1: 4$ naph thohydro-

quinone disuccinate given by intramuscular injection at 163 hours. Clotting activity remained at normal despite the following findings: Faecal fats-total, $33.7 \%$; split, $29.7 \%$ of total. Icteric index, 333. Laevulose tolerance test: $30 \mathrm{~min} ., 6 \mathrm{mg}$. per $100 \mathrm{c.cm}$.; $60 \mathrm{~min}$., $6 \mathrm{mg}$. ; and $120 \mathrm{~min} ., 7 \mathrm{mg}$. Died at 264 hours, apparently from hepatic dysfunction.

Case 5551.-Classical Caesarean section of election for hypertension. Birth weight, $9 \frac{1}{4} \mathrm{lb}$. Birth condition satisfactory. Persistent ooze from heel-stab began at 29 hours. Intramuscular injection of $2.5 \mathrm{mg}$. 2-methyl-1:4-naphthoquinone at 31 hours led to cessation of bleeding two hours later.

Case 6765.-6-para. Normal labour (duration 11 hours). Spontaneous delivery. Birth weight, $5 \frac{1}{4} \mathrm{lb}$. Copious melaena first noticed at 54 hours of age. Intravenous injection 2-methyl1:4-naphthohydroquinone disuccinate at 71 hours. No further fresh bleeding. Melaena persisted for further 20 hours, suggesting a bleeding-point high in the intestinal tract.

In three cases (Figs. 1, 3, and 4) vitamin $K$ analogues were given after haemotherapy had failed to control haemorrhage or to raise and maintain the prothrombin index. In each instance an immediate and lasting response was obtained both clinically and in the level of the prothrombin index - an effect too rapid to be influenced by any concomitant tendency to spontaneous recovery, and in

Table, showing Prothrombin Index

\begin{tabular}{c|c|c|c}
\hline \multirow{2}{*}{ Case No. } & \multirow{2}{*}{ Before Vitamin K } & \multicolumn{2}{|c}{ After Vitamin K } \\
\cline { 3 - 4 } \cline { 3 - 4 } & & Less than 12 hours & Less than 24 hours \\
\hline 6295 & 35 & 70 & 78 \\
6633 & 24 & - & 85 \\
6912 & 33 & & 65 \\
\hline
\end{tabular}

marked contrast to the results of the other methods tried. In three other cases which have been treated by injection of $2.5 \mathrm{mg}$. of 2-methyl-1:4-naphthoquinone the prothrombin index estimations have been made less frequently than in the cases already recorded. In each instance, however, frank bleeding stopped in a short time and the prothrombin index rose to and remained at normal or nearly normal levels (see Table).

\section{ICterus Gravis}

Two cases of icterus gravis showed spontaneous haemorrhages which were treated successfully by the intramuscular injection of $2.5 \mathrm{mg}$. of 2-methyl-1:4naphthoquinone in oil. The prothrombin index and certain other details of Case 7152 are charted in Fig. 6.* From the therapeutic point of view the i n t e r e s t i n $\mathrm{g}$ feature is the rapid and sustained effect given by vitamin $\mathbf{K}$ analogue e ven when a laevulosetolerance test indicated a considerable depression of liver function.

\section{Discussion}

In spite of the proved effect of vitamin $\mathrm{K}$ in increasing the clotting activity of blood in such a way that spontaneous bleeding ceases in a very short time, it has been authoritatively stated that the administration of adult blood intravenously or by repeated intramuscular injections not only is a safer measuie for general use but gives "results ... among the most striking in therapeutics" (Lancet, 1940, 1941). Clearly the very small and fleeting response even to the repeated injection of adult blood into the buttocks can be instrumental in controlling the haemorrhagic tendency only when the prothrombin index is already rising spontaneously. Moreover, repeated injection of so much blood is not devoid of danger. Blood transfusion in the newborn is a procedure that can be undertaken only in hospital, and even there may be followed by untoward

* These cases will be recorded in more detail later by Dr. J. L. Henderson, to whom I am grateful for the reticulocyte and haemoglobin estimations. 
reactions. The evidence from two cases treated by transfusion supports the observation that even when a comparatively large volume of blood is given to an adult the effect upon the clotting activity is transient (Stewart, 1939). It appears from Case 6947 that when a transfusion of average volume is given the immediate effect upon the prothrombin index is dramatic (more rapid, though more limited, than can be obtained from the injection of vitamin $\mathrm{K}$ analogue alone). Unless, however, this early rise is supported by concurrent spontaneous restoration the prothrombin may fall to its original level and bleeding recur in a very few hours.

The prompt and maintained increase in the plasma prothrombin and the rapid control of haemorrhage (within two hours of administration where bleeding was superficial) after the injection of vitamin $\mathrm{K}$ analogues are manifestly quite independent of any coexistent tendency to spontaneous recovery. Moreover, $2.5 \mathrm{mg}$. of 2-methyl-1:4naphthoquinone intramuscularly restored the prothrombin index and maintained it at adult levels even when the laevulose-tolerance test indicated deficient hepatic function (Case 7152). The site of injection (intravenous or intramuscular) has no effect upon the rapidity of action, and there is no material difference between oil-soluble and water-soluble preparations. The simplicity of this method and the extreme rarity of conditions in which vitamin $K$ analogues will not be effective in arresting the haemorrhagic tendency suggest that one of them should be employed first in all cases of spontaneous and persistent bleeding in the newborn. It is probable that in the most severe cases, in which prolonged or massive haemorrhage is exsanguinating the patient, simultaneous treatment by transfusion and injection of vitamin $\mathrm{K}$ analogue should be given. The rapid action of the transfusion in elevating the haemoglobin and plasma prothrombin levels would then be reinforced by the slightly slower and much more sustained effect of the vitamin $\mathrm{K}$ analogue on the clotting activity of the blood.

I am much indebted to Dr. E. McCallum, who has helped me with the prothrombin estimations in several of the cases described ; and to Dr. J. L. Henderson for his interest in bringing some of these cases to my notice and for his assistance in other ways. Also I wish to thank Dr. W. F. T. Haultain, Dr. Douglas Miller, Prof. R. W. Johnstone, and Prof. Charles McNeil, who have given me every. facility to carry out these investigations on the cases under their care. I am indebted to Glaxo Laboratories Ltd. and to Roche Products Limited for generous supplies of vitamin $\mathrm{K}$ analogues.

REFERENCES

Hobson, F. C. G., and Witts, L. J. (1940). Lancet, 2, 247.

Illingworth C. F.W. (1939), Ibid., 1, 1031

Innes, J., and Davidson, L. S. P. (1941). British Medical Journal, 1, 621.

Lancet, 1940, 1, 650 .

Lancet, 1941, 1, 250 .

Macpherson, A. I. S., McCallum, E., and Haultain, W. F. T. (1940). British Medical Journal, 1, 839.

Nygaard, K. K. (1939). Acta obstet. gynec. scand., 19, 361

Quick, A. J., Stanley-Brown, M., and Bancroft, F. W. (1935). Amer. J. med. Sci., 190, 501 .

Rodda, F. C. (1920). Amer. J. Dis. Child., 19, 269

Schloss, O. M., and Commiskey, L. J. J. (1911). Ibid., 1, 276.

- (1912). Ibid., 3, 216 .

Stewart, J. D. (1939). Ann. Surg., 109, 588

Tallerman, K. H. (1937). Eden and Holland's Manual of Obstetrics, p. 615, London.

Waddell, W. W., and Guerry, D. (1939). J. Amer. med. Ass., 112, 2259.

Whipple, G. H.' (1913). Arch. intern. Med., 12, 637.

Ziffren, S. E., Owen, C. A., Hoffman, G. R., and Smith, H. P. (1939). Proc. Soc. exp. Biol., N.Y.,, 40, 595.

The borough of Chelmsford, with an estimated population of 33,040, reports twenty-eight deaths of children under 1 year during 1940, and only ten deaths among young persons between 1 and 25 years. An attempt was made to establish a day nursery for children between 2 and 5, but the scheme had to be abandoned, chiefly owing to the difficulty of bringing and collecting children in the black-out, and of obtaining money, staff, and accommodation. The M.O.H. notes a good response to the diphtheria immunization campaign, and only three cases were reported during the year, with no deaths.

\section{THE CAUSES UNDERLYING THE RECENT INCREASED INCIDENCE OF AND MORTALITY FROM TUBERCULOSIS IN GLASGOW}

BY

STUART LAIDLAW, B.Sc., M.D., D.P.H., D.P.A. AND

DUNCAN MACFARLANE, M.B., Ch.B., D.P.H.

(From the Public Health Department, Glasgow)

\section{Pulmonary. Tuberculosis}

It would appear that for five years preceding the outbreak of war in 1939 the incidence of and the mortality from pulmonary tuberculosis were tending to stabilize themselves in Glasgow at figures of around 1,650 notifications and 960 deaths per annum. During the first year of war the returns under the above two headings were 1,908 and 1,177 respectively, a rise of approximately 250 notifications and 200 deaths. This increased incidence and mortality is being maintained during 1941.

The following table shows the total number of notifications and deaths from pulmonary tuberculosis during the past seven years, together with a forecast for 1941 based on the returns for the first half of the year:

\begin{tabular}{c|c|c||c|c|c}
\hline Year & Notifications & Deaths & Year & Notifications & Deaths \\
\hline 1934 & 1,646 & 873 & 1938 & 1,748 & 960 \\
1935 & 1,757 & 972 & 1939 & 1,574 & 972 \\
1936 & 1,647 & 979 & 1940 & 1,908 & 1,177 \\
1937 & 1,654 & 955 & $1941^{*}$ & 2,190 & 1,342 \\
\hline
\end{tabular}

* Estimated figure-i.e., twice the notifications and deaths during the firs half of 1941 .

The seasonal incidence of notifications from pulmonary tuberculosis for the years 1939, 1940, and 1941 was studied when it was found that the graphs for 1940 and 1941 followed closely the path of the graph for 1939, but at a slightly higher level. It was observed that the rise in notifications during 1940 and 1941 was normally distributed throughout the year, and did not occur in any one particular season.

The age and sex distribution of the notified cases of pulmonary tuberculosis for 1939 and 1940 are tabulated below:

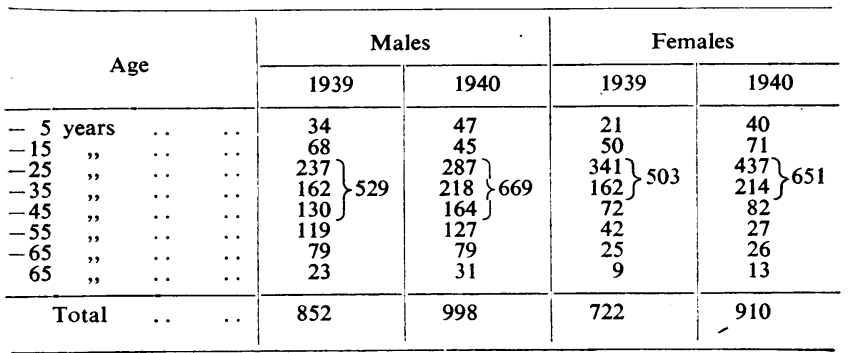

The total number of notifications was 1,57.4 in 1939 and 1,908 in 1940. During the first half of 1941 there were 1,095 notifications and 671 deaths-figures that indicate that the disease is continuing to increase in incidence.

It will be seen from the table that the increased incidence has taken place almost entirely between the ages of 15 and 45 in males and 15 and 35 in females, and that both sexes show an all-round increase of $20 \%$ over the 1939 returns.

\section{Non-pulmonary Tuberculosis}

The comparative figures for non-pulmonary tuberculosis for 1939 and 1940 also show that a considerable rise in the number of notifications and deaths from this form of tuber- 